\title{
QUANTIFICAÇÃO DAS CLASSES DE EROSÃO POR TIPO DE USO DO SOLO NO MUNICÍPIO DE FRANCA - SP ${ }^{1}$
}

\author{
PAULA F. ENDRES ${ }^{2}$, TERESA C. T. PISSARRA ${ }^{3}$, MAURÍCIO J. BORGES ${ }^{4}$, \\ WALTER POLITANO
}

\begin{abstract}
RESUMO: Impactos ambientais causados pelas atividades agropecuárias sobre o meio rural podem ser constatados quando são analisadas as paisagens da região. Vários estudos demonstraram que informações da paisagem obtidas a partir de imagens fotográficas são indispensáveis para $o$ diagnóstico do processo erosivo do solo, aspecto indispensável no planejamento conservacionista. Neste trabalho, utilizando-se de técnicas de fotointerpretação, foi realizada a quantificação das classes de erosão acelerada no município de Franca - SP, relacionando-as com os tipos de cobertura vegetal. A coleção de fotografias aéreas empregadas foi produzida pela Base Aerofotogrametria e Projetos S.A., com escala aproximada 1:35.000, em outubro de 1990. Elaboraram-se cartas temáticas do uso/ocupação do solo e dos estados erosivos presentes em cada tipo de cobertura vegetal do solo, estabelecendo-se, em seguida, as relações entre a erosão acelerada e os tipos de comunidades vegetais do município de Franca. Os resultados obtidos mostraram que, nesse município, o solo agrícola encontra-se relativamente conservado, apresentando $74,23 \%$ da área com erosão laminar ligeira/moderada. Os diferentes usos/ocupações do solo influenciaram de modos distintos na manifestação do processo erosivo.
\end{abstract}

PALAVRAS-CHAVE: sensoriamento remoto, erosão, uso/ocupação do solo.

\section{MEASUREMENT OF THE EROSION CLASSES AND LAND USE IN FRANCA MUNICIPALITY - SP, BRAZIL}

\begin{abstract}
Environment impacts caused by farming activities on agricultural management can be evidenced when the land use is analyzed. Some studies had demonstrated that, the information of the land use from photographic images is essential for identifying the erosive process, indispensable aspect in planning for better land management. In this work, using photointerpretation techniques, the measurement of the erosion classes in Franca Municipality - SP, Brazil, was carried through, relating them with the land uses. The BASE - Aerofotogrametria e Projetos S.A. took the used air photograph collection, with the approach scale of 1:35.000, in October of 1990. The thematic map of land use and the occurrence of classes of erosive process were elaborated and the relations between them were analyzed. The Municipality of Franca is relatively conserved, showing $74.23 \%$ of the area with sheet and rill erosion. Different land use had influenced the manifestation of the erosive process.
\end{abstract}

KEYWORDS: remote sensing, erosion, land use.

\footnotetext{
${ }^{1}$ Extraído do trabalho de graduação em Agronomia do primeiro autor.

${ }^{2}$ Eng $^{\text {a }}$ Agrônoma.

${ }^{3}$ Eng ${ }^{a}$ Agrônoma, Profa. Dra., Departamento de Engenharia Rural, UNESP, Jaboticabal - SP.

${ }^{4}$ Eng $^{\mathrm{O}}$ Agrônomo, Doutor em Agronomia (ProduçãoVegetal) pela UNESP, Jaboticabal - SP.

${ }^{5}$ Eng ${ }^{\mathrm{o}}$ Agrônomo, Prof. Aposentado, Departamento de Engenharia Rural, UNESP, Jaboticabal - SP.

Recebido pelo Conselho Editorial em: 3-11-2003

Aprovado pelo Conselho Editorial em: 12-12-2005
} 


\section{INTRODUÇÃO}

Os processos erosivos ocorrem naturalmente no meio ambiente, de forma lenta e gradual, causando, no decorrer da evolução do globo terrestre, mudanças no relevo e na vegetação (BERTONI \& LOMBARDI NETO, 1990). A intervenção humana acelera esses processos erosivos por meio da ocupação e uso intensivo do solo. A erosão antrópica, identificada como erosão acelerada, remove paulatinamente as camadas superficiais do solo, chegando a formar sulcos e ravinas, quando o escoamento da água é torrencial (POLITANO et al., 1992).

Entretanto, quando o solo é protegido por cobertura vegetal densa e com sistema radicular abundante, o processo erosivo é menos intenso. CASSOL (1981) comentou que a cobertura vegetal intercepta as gotas de chuva, dissipa a energia cinética da queda e evita o seu impacto direto sobre a superfície, o que reduz o grau de desagregação do solo. Além disso, a cobertura vegetal reduz a velocidade do escoamento das águas superficiais pela formação de barreiras mecânicas, o que diminui o transporte de sedimentos.

Segundo BERTOL et al. (1989), a cobertura (viva ou morta) do solo pode promover redução nas perdas de solo de até $90 \%$ e na velocidade da enxurrada de até $62 \%$. Esses autores concluíram que, uma vez reduzido o efeito do impacto direto das gotas de chuva sobre a superfície, o tamanho dos agregados transportados pela enxurrada passa a ser em função do método de preparo do solo e/ou tipo de equipamento utilizado.

Para estabelecer a prática necessária para cada área de cultivo, são fundamentais as caracterizações do solo, da topografia, da geomorfologia, da hidrologia e da erosão acelerada. O sensoriamento remoto entra nesse contexto como ferramenta muito apropriada para o planejamento e prevenção de áreas potencialmente de risco. A utilização das informações das fotografias aéreas facilita a reunião dos elementos empregados no planejamento conservacionista (AMARAL, 1998; POLITANO et al., 1992; POLITANO et al., 1995).

Este trabalho teve como principal objetivo avaliar, pelo uso de técnicas de fotointerpretação, a erosão acelerada do solo no município de Franca - SP, para relacioná-la com as condições das diferentes comunidades vegetais.

\section{MATERIAL E MÉTODOS}

A área de estudo está localizada no município de Franca, na porção nordeste de São Paulo, cujas coordenadas geográficas são latitudes $20^{\circ} 25^{\prime} \mathrm{S}$ a $24^{\circ} 41^{\prime} \mathrm{S}$ e longitudes $47^{\circ} 08^{\prime}$ a $47^{\circ} 33^{\prime} \mathrm{WGr}$. O município apresenta extensão territorial de $607 \mathrm{~km}^{2}$ e altitude média de $1.040 \mathrm{~m}$ e está inserido na bacia hidrográfica do Sapucaí/Grande, entre as microbacias dos rios Canoas e Sapucaí-Mirim. O clima da região é Cwa (classificação Köeppen, clima mesotérmico com inverno seco e verão quente), com médias anuais de temperatura de $23,5^{\circ} \mathrm{C}$ e de precipitação de $1.520 \mathrm{~mm}$ ao ano. A precipitação média do mês mais seco é de $35 \mathrm{~mm}$ e dos meses mais quentes (dezembro a fevereiro) é de $1.400 \mathrm{~mm}$ (SÃO PAULO, 1990; FRANCA, 2002; IBGE, 2002).

Os valores das médias mensais de temperatura e precipitação do município de Franca, referentes ao período de análise, constam na Figura 1.

A geologia da região de Franca é composta pelas formações do Grupo São Bento (Formações Serra Geral, Botucatu e Pirambóia), formadas por faixas de arenitos conglomeráticos, de depósitos continentais e de sedimentos de natureza areno-argilosa de caráter variado quando associados às encostas. As áreas de rochas basálticas no Estado de São Paulo sustentam relevos de Cuestas Basálticas que se caracterizam morfologicamente por apresentar relevo escarpado nos limites com a Depressão Periférica, seguido de sucessão de grandes plataformas estruturais de relevo suavizado, inclinadas em direção à calha do Rio Paraná. Essas duas feições principais constituem a escarpa e o reverso das cuestas (SÃO PAULO, 1981a, b). 


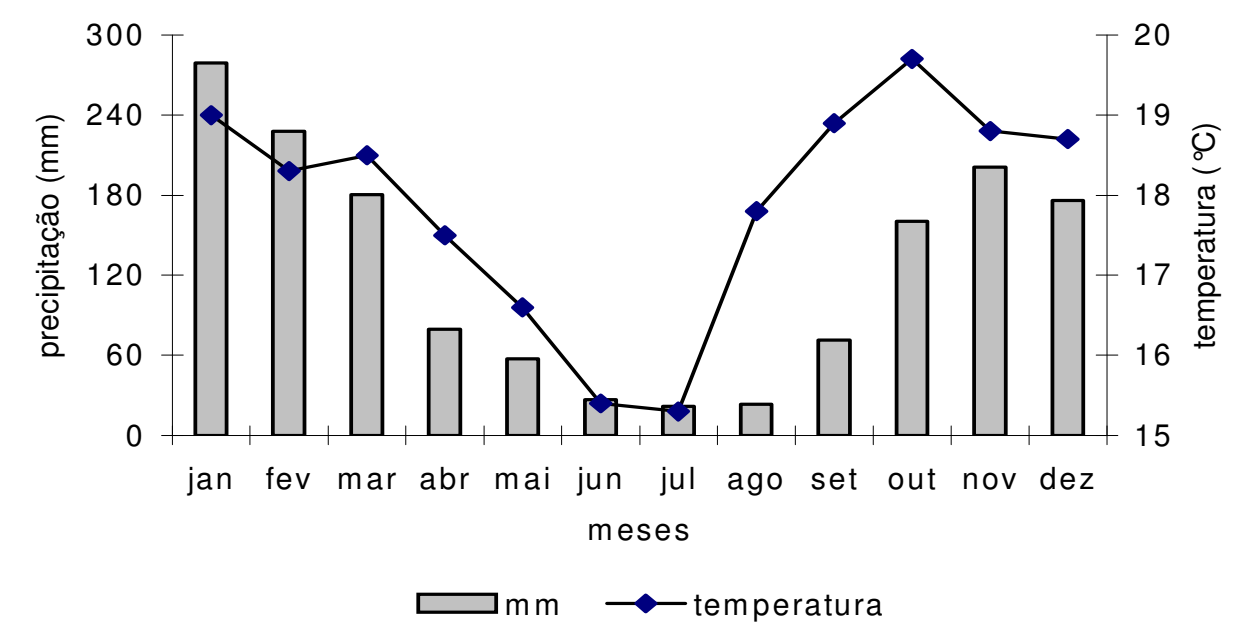

FIGURA 1. Médias mensais de temperatura $\left({ }^{\circ} \mathrm{C}\right)$ e precipitação $(\mathrm{mm})$ do município de Franca referentes ao ano de 1990 (BRASIL, 1992).

Segundo a COMISSÃO DE SOLOS (1960), as unidades predominantes dos solos são o Latossolo Vermelho-Amarelo fase arenosa (LVA) e o Latossolo Roxo (LR). Esses solos diferem entre si em relação à textura (o LVA apresenta teores de argila e silte mais baixos), à estrutura (o LR apresenta porosidade total maior) e à fertilidade (o LR apresenta maiores índices de capacidade de troca de cátions, soma de bases e saturação de bases). Atualmente, essas unidades são classificadas de acordo com o mapa pedológico do Estado de São Paulo, segundo OLIVEIRA et al. (1999), como Latossolos Vermelhos (LV).

A vegetação original atual se restringe a alguns cerrados sobre alguns espigões em solos arenosos, de matas latifoliadas e subcadifólias em porções de relevo acidentado e trechos de matagaleria.

A coleção de fotografias aéreas verticais, pancromáticas, com escala aproximada de 1:35.000, produzida pela Base-Aerofotogrametria e Projetos S.A. e referente ao vôo realizado em outubro de 1990, foi o principal material utilizado na elaboração dos mapas-base temáticos. Os equipamentos utilizados para auxiliar na análise das imagens fotográficas foram as lupas de aumento (10 vezes), a mesa de luz, o estereoscópio de espelho com binoculares da marca Zeiss e o planímetro polar A. OTT. Para a confecção do mapa-base (demarcação das comunidades vegetais, rede de drenagem e erosão acelerada), utilizaram-se templetos de filme de poliéster. As cartas topográficas da coleção Carta do Brasil, editadas por BRASIL (1971), foram empregadas como material de apoio para o traçado dos limites da área de estudo. As folhas utilizadas foram as SF 22-X-D-III-2, respectivamente para Franca, Pedregulho, Capetinga e Jeriquara.

A elaboração do mapa-base foi realizada empregando-se as fotografias aéreas e adotando-se processo de montagem baseado no método de triangulação gráfica, conforme descrição de LOPES VERGARA (1971). Os procedimentos foram os seguintes: 1. Identificação dos centros principais e transferidos nas fotografias aéreas; 2. Identificação de seis pontos auxiliares em cada fotografia aérea; 3. Identificação da linha de vôo em cada faixa de fotografias; 4. Ligação dos pontos auxiliares para estabelecer os limites da área de trabalho em cada fotografia; 6. Montagem das fotografias (com uso de templetos), ajuste de posição de cada fotografia (com auxílio dos conjuntos de pontos demarcados), e 7. Transferência dos pontos de controle para a folha-base.

Utilizando-se de técnicas de fotointerpretação e análise estereoscópica, foram identificadas e traçadas a rede hidrográfica e a malha viária, delimitando-se a área das comunidades vegetais e os estados de erosão acelerada, segundo metodologias de AMARAL (1998) e POLITANO et al. (1995). 


\section{RESULTADOS E DISCUSSÃO}

As comunidades vegetais analisadas para a confecção do mapa temático de usos/ocupação do solo foram aquelas com áreas mais representativas, sendo elas: mata, capoeira, várzea, reflorestamento, pastagem, canavial, cafezal e culturas não-individualizadas. A área sem cobertura vegetal foi denominada como solo exposto.

A descrição das comunidades vegetais e dos estados da erosão acelerada e seus respectivos padrões fotográficos constam nas Tabelas 1 e 2.

TABELA 1. Características e padrões fotográficos das comunidades vegetais do município de Franca SP.

\begin{tabular}{|c|c|}
\hline $\begin{array}{c}\text { Comunidades } \\
\text { Vegetais }\end{array}$ & Padrão Fotográfico \\
\hline Mata & 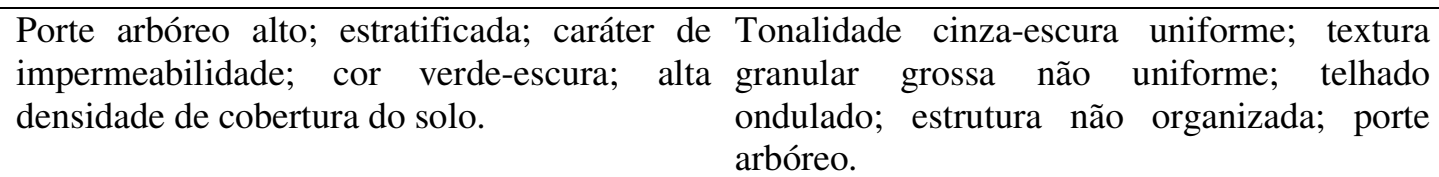 \\
\hline Capoeira & $\begin{array}{ll}\begin{array}{l}\text { Porte arbóreo baixo e arbustivo; cor verde- } \\
\text { escura; alta densidade de cobertura vegetal. }\end{array} & \begin{array}{l}\text { Tonalidade cinza-escura uniforme; textura } \\
\text { média/fina e fina; telhado plano; estrutura não } \\
\text { organizada; porte arbustivo ou arbóreo. }\end{array} \\
\end{array}$ \\
\hline Várzea & $\begin{array}{l}\text { Vegetação localizada nas planícies de Tonalidade cinza-escura e média; textura } \\
\text { inundação, com espécies geralmente média e fina; telhado plano e ligeiramente } \\
\text { higrófilas, porte herbáceo e arbustivo; silhueta ondulado; estrutura não organizada e macia; } \\
\text { em moita; cor verde-escura, escuro-médio; porte rasteiro e arbustivo. } \\
\text { alta densidade de cobertura do solo. }\end{array}$ \\
\hline Reflorestamento & $\begin{array}{ll}\text { Comunidade florestal de eucalipto ou pínus; } & \text { Tonalidade cinza-escura uniforme; textura } \\
\text { porte arbóreo alto; cor verde médio e escuro; granular fina e muito fina; telhado plano } \\
\text { densidade de cobertura do solo média/alta; } & \text { estrutura organizada em alinhamentos; porte } \\
\text { alinhamento médio. } & \text { arbóreo. }\end{array}$ \\
\hline Pastagem & $\begin{array}{ll}\text { Campos antrópicos (áreas de pastoreio); porte } & \text { Tonalidade cinza-clara, claro/médio uniforme; } \\
\text { herbáceo baixo ou médio; cor verde-médio textura granular muito fina, uniforme; } \\
\text { claro; alta densidade de cobertura do solo. } & \text { estrutura maciça; porte rasteiro. }\end{array}$ \\
\hline Cafezal & $\begin{array}{l}\text { Comunidade antrópica de plantas de café; Tonalidade cinza-escur } \\
\text { porte arbustivo; silhueta colunar; cor verde- plano; estrutura alinhac } \\
\text { escura; densidade de cobertura do solo } \\
\text { média/alta; alinhamentos em nível. }\end{array}$ \\
\hline Canavial & $\begin{array}{l}\text { Comunidade antrópica com a cana-de-açúcar; Tonalidade cinza médio-clara e muito clara; } \\
\text { porte herbáceo e arbustivo; silhueta em moita; textura aveludada, muito fina, uniforme; } \\
\text { cor verde-clara e médio; alta densidade de telhado plano; estrutura maciça e em } \\
\text { cobertura do solo (desenvolvido), baixa e alinhamentos em nível; porte herbáceo e } \\
\text { média (soqueira e novos); alinhamento em arbustivo. } \\
\text { nível. }\end{array}$ \\
\hline $\begin{array}{l}\text { Culturas não- } \\
\text { individualizadas }\end{array}$ & $\begin{array}{l}\begin{array}{l}\text { Áreas com culturas herbáceas não } \\
\text { identificadas. }\end{array} \\
\begin{array}{l}\text { Tonalidade cinza-clara; textura uniforme, de } \\
\text { granulação variável; telhado plano; porte } \\
\text { herbáceo. }\end{array}\end{array}$ \\
\hline Solo exposto & $\begin{array}{lll}\text { As cores naturais dos solos se situam entre o } & \text { Tonalidades claras ou brancas; materiais de } \\
\text { vermelho e o amarelo e entre o branco e o } & \text { mesma cor exibem tonalidade diferente } \\
\text { preto. } & \text { segundo a classe textural que apresentam (os } \\
& \text { finos tendem a cinzas mais escuros que os } \\
& \text { grosseiros). }\end{array}$ \\
\hline
\end{tabular}


TABELA 2. Padrões fotográficos dos estados da erosão acelerada no município de Franca - SP.

\begin{tabular}{ll}
\hline \multicolumn{1}{c}{ Estado da Erosão Acelerada } & \multicolumn{1}{c}{ Padrão Fotográfico } \\
\hline 1) Não aparente & $\begin{array}{l}\text { Sem alterações da imagem relacionadas com a erosão acelerada em } \\
\text { áreas de mata, capoeira, vegetação de várzea e eucaliptais. }\end{array}$ \\
\hline \multirow{2}{*}{ 2) Laminar ligeira/moderada } & $\begin{array}{l}\text { Sem alterações da imagem relacionadas com a erosão acelerada em } \\
\text { áreas das outras comunidades vegetais. Tonalidade mais clara, } \\
\text { geralmente associada aos topos e meia-encosta. }\end{array}$ \\
\hline 3) Em sulcos freqüentes & $\begin{array}{l}\text { Alterações ligeiras da forma e tonalidade. Alterações típicas } \\
\text { relacionadas com a presença de sulcos (filamentos no sentido do } \\
\text { declive com tonalidade e textura alteradas com pouca freqüência). }\end{array}$ \\
\hline 4) Em sulcos muito freqüentes & $\begin{array}{l}\text { Alterações típicas relacionadas com a presença de sulcos e a remoção } \\
\text { de camadas finas em áreas extensas das partes declivosas do terreno } \\
\text { e em lençol }\end{array}$ \\
(filamentos no sentido do declive com tonalidade e textura alterada \\
com muita freqüência).
\end{tabular}

As áreas de matas, capoeiras e várzeas apresentaram características semelhantes quanto à tonalidade e estrutura. A diferença entre a área de mata e a área de reflorestamento é que a última apresenta telhado plano indicando uma única espécie arbórea e estrutura organizada em alinhamentos.

Nas aéreas de pastagens, foi identificado o porte rasteiro da comunidade vegetal instalada, sendo a diferença primordial para as outras coberturas analisadas. Em campo sujo, nota-se a presença irregular e espaçada de vegetação com porte herbáceo, sendo interpretado como se nessa área a pastagem tivesse sido abandonada. As áreas de campo limpo compreendem as pastagens na forma de cultura, apresentando textura granular muito mais fina e uniforme que as áreas de campo sujo.

As áreas de canaviais apresentam-se com características muito semelhantes às áreas de culturas não-individualizadas: tonalidade cinza-clara, textura uniforme, telhado plano e porte herbáceo. Por outro lado, diferem-se quanto ao sistema de cultivo, em que o canavial em formação apresenta maior espaçamento entre as linhas de plantio, as quais podem ser visualizadas nas fotografias.

As áreas de cafezais distinguem-se das outras por apresentarem textura fina, telhado plano, estrutura alinhada e porte arbustivo.

As áreas de solo exposto apresentam tonalidades claras ou brancas, facilmente identificáveis nas fotografias aéreas.

As áreas dos estados de erosão acelerada aparecem com tonalidades mais claras, geralmente associadas aos topos e meia-encosta. Essa tonalidade reflete a exposição do subsolo e contrasta com o tom mais escuro dos locais preservados. Os sulcos foram identificados pela ocorrência de tons mais claros num padrão linear e na direção do declive, enquanto as voçorocas foram diferenciadas dos sulcos e do sistema fluvial, respectivamente, pela definição da profundidade e da relação largura/profundidade, observados no modelo espacial reproduzido pelo estereoscópio.

As áreas de abrangência de cada tipo de cobertura vegetal e estados de erosão acelerada são apresentados na Tabela 3. As áreas de matas, capoeiras e várzeas foram agrupadas como áreas de preservação natural, pois relacionam-se com formações vegetais originais da região e formações que não estão sofrendo ações antrópicas, correspondendo às áreas protegidas por lei (Reserva Legal e Áreas de Preservação Permanente). 
TABELA 3. Áreas de abrangência de cada tipo de cobertura vegetal e estados de erosão acelerada no município de Franca - SP (1990).

\begin{tabular}{|c|c|c|c|c|c|c|c|c|c|c|c|c|}
\hline \multirow{3}{*}{$\begin{array}{l}\text { Cobertura } \\
\text { Vegetal }\end{array}$} & \multicolumn{12}{|c|}{ Estados de Erosão do Solo** } \\
\hline & \multicolumn{2}{|c|}{1} & \multicolumn{2}{|c|}{2} & \multicolumn{2}{|c|}{3} & \multicolumn{2}{|c|}{4} & \multicolumn{2}{|c|}{5} & \multicolumn{2}{|c|}{ Total } \\
\hline & (ha) & $\%$ & (ha) & $\%$ & (ha) & $\%$ & (ha) & $\%$ & (ha) & $\%$ & (ha) & $\%$ \\
\hline $\begin{array}{l}\text { Preservação } \\
\text { Natural* }\end{array}$ & 3.894 & 10,8 & - & - & - & - & - & - & - & - & 3.894 & 10,8 \\
\hline Reflorestamento & 249 & 0,7 & - & - & - & - & - & - & - & - & 249 & 0,7 \\
\hline Canaviais & - & - & 1.385 & 3,8 & 145 & 0,4 & 0 & 0 & 0 & 0 & 1.529 & 4,2 \\
\hline Cafezais & - & - & 5.541 & 15,3 & 528 & 1,5 & 118 & 0,3 & 2 & 0 & 6.189 & 17,1 \\
\hline $\begin{array}{l}\text { Culturas-não } \\
\text { individualizadas }\end{array}$ & - & - & 9.978 & 27,6 & 1.415 & 3,9 & 596 & 1,6 & 17 & 0 & 12.007 & 33,2 \\
\hline Campo limpo & - & - & 5.869 & 16,2 & 1.103 & 3,1 & 244 & 0,7 & 37 & 0,1 & 7.253 & 20,1 \\
\hline Campo sujo & - & - & 4.462 & 12,3 & 516 & 1,4 & 52 & 0,1 & 11 & 0 & 5.041 & 13,9 \\
\hline Total & 4.144 & 11,5 & 27.235 & 75,3 & 3.707 & 10,3 & 1.011 & 2,8 & 67 & 0,2 & 36.164 & 100,0 \\
\hline
\end{tabular}

Na análise da Tabela 3, constata-se que esse município se encontra relativamente conservado quanto à erosão acelerada, apresentando 31.378 ha $(86,8 \%$ da área) com erosões laminares nãoaparente a ligeira/moderada (estados de erosão 1 e 2).

As áreas onde a erosão acelerada se encontra mais intensa (relacionada aos processos 3 e 4), foram observadas em locais de topografia mais movimentada, a qual corresponde à Serra de Franca e seus limites. Nessas áreas, observa-se alta suscetibilidade ao movimento de massas, apresentando relevo resultante de forte entalhamento da drenagem de ocorrência natural e generalizada (SÃO PAULO, 1981a).

Nas áreas que apresentam situações isoladas de processos erosivos intensos e voçorocas (estado de erosão 5), o manejo conservacionista não se encontra adequado à cobertura vegetal e à declividade do local, pois são áreas sujeitas ao surgimento de ravinas e sulcos a partir do simples desmatamento das cabeceiras de drenagem e de matas ciliares, o mesmo observado por NAKAZAWA et al. (1994).

Na condição de áreas com preservação natural e reflorestamento, observa-se o estado de erosão 1. Isso ocorre tendo em vista a condição de solos sob vegetações de floresta e de gramínea que possuem a característica de minimizar o processo intenso do escoamento superficial das águas das chuvas (enxurrada). Na vegetação de floresta, as copas das árvores de diferentes alturas oferecem quebra de intensidade da chuva, e o solo encontra-se comumente revestido por camada de material orgânico (serrapilheira).

Na cobertura vegetal de cana-de-açúcar, ocorreu predomínio do estado de erosão 2 (1.385 ha). A cultura de cana-de-açúcar oferece proteção maior ao solo, principalmente por apresentar intenso perfilhamento na sua fase inicial de crescimento e intenso crescimento do colmo principal, propiciando, assim, cobertura vegetal mais homogênea e densa. Além do mais, como gramínea de cultivo semiperene, seu sistema radicular oferece reposição contínua de material orgânico ao solo, restruturando-o e ativando a porção viva do ambiente (microrganismos e microfauna), melhorando as condições de retenção de água e seu percolamento pelo perfil do solo.

A cultura do café apresenta-se em duas fases críticas em relação à suscetibilidade à erosão: durante o primeiro ano de cultivo (na sua implantação) e no inverno, quando ocorre a queda de folhas. Correlacionando-se a época em que as fotografias foram tiradas (outubro de 1990), com valores 
médios mensais de temperatura e de pluviometria (Figura 1), observa-se que, nos cafezais, o processo erosivo foi intensificado quando ocorreram as primeiras chuvas desse período, pois o solo ainda estava desprotegido e a cultura retomava seu crescimento vegetativo.

Nas áreas de pastagens, observa-se a ocorrência de processos erosivos intensos (estados de erosão 3; 4 e 5) em torno de 5,4\% da área total analisada (1.964 ha), com presença mais marcante nas pastagens cultivadas (campo limpo). As pastagens são unidades vegetais que melhoram as condições estruturais do solo e diminuem o processo erosivo pelo aumento da superfície rugosa; entretanto, esses benefícios somente são observados quando essa cultura é conduzida adequadamente.

Os meses que antecederam o levantamento fotográfico, no ano de 1990 (Figura 1), foram de baixa precipitação, considerados os mais secos do ano. Nessas condições climáticas, o crescimento vegetativo é menor, fazendo com que a proteção oferecida ao solo seja menor. Portanto, pode-se inferir que as áreas que se apresentam com processos erosivos intensos, estão degradadas pelo manejo inadequado.

As áreas de culturas não-individualizadas (culturas anuais) apresentaram maiores índices de processo erosivo intenso e voçorocas (estados de erosão 3; 4 e 5), em torno de 2.029 ha. Por serem culturas de ciclo curto, práticas culturais são intensamente aplicadas nessas áreas, podendo haver até cinco cultivos em dois anos agrícolas. Nesse sentido, o manejo conservacionista a ser adotado deve ser mais severo do que em outras comunidades vegetais estudadas (culturas perenes e semiperenes), principalmente quando se associa esse tipo de uso do solo com altas declividades.

As áreas de solo exposto apresentam-se em torno de 12\% (71,05 ha) com erosão em sulcos freqüentes (estado de erosão 3). Mesmo assim, pode-se concluir que são áreas em estado de preparo adequado, observando-se em poucas áreas sulcos muito freqüentes e ravinas (estados de erosão 4 e 5).

\section{CONCLUSÕES}

A área rural do município de Franca encontra-se relativamente conservada quanto à erosão acelerada, sendo identificada, aproximadamente, em 3/4 de sua extensão global, as erosões laminares não-aparente a ligeiro/moderada. O tipo de uso/ocupação do solo influenciou na manifestação dos processos erosivos quanto à intensidade do processo e à área de abrangência de cada um deles. Em relação à área de abrangência dos estados da erosão acelerada, em cada comunidade vegetal, constatou-se a seguinte ordem decrescente: café, campo sujo, campo limpo e cana-de-açúcar apresentaram os processos 2; 3; 4 e 5; a cana-de-açúcar apresentou os processos 2 e 3; áreas com preservação natural e reflorestamento apresentaram o processo erosivo 1.

\section{REFERÊNCIAS}

AMARAL, A.L. Estudo por fotointerpretação da influência do tipo de ocupação do solo na manifestação da erosão acelerada no Município de Araraquara - SP. 1998. 45 f. Monografia (Trabalho de Graduação) - Faculdade de Ciências Agrárias e Veterinárias, Universidade Estadual Paulista, Jaboticabal, 1998.

BERTOL, I.; ROGO, N.P.; LEVIEN, R. Cobertura morta e métodos de preparo do solo na erosão hídrica em solo com crosta superficial. Revista Brasileira de Ciência do Solo, Campinas, v.13, n.3, p.373-9, 1989.

BERTONI, J.; LOMBARDI NETO, F. Conservação do solo. São Paulo: Ícone, 1990. 355 p.

BRASIL. Ministério da Agricultura e Reforma Agrária. Normas climatológicas (1961-1990). Brasília, 1992. p.8, 18, 53. 
BRASIL. Ministério do Planejamento. Fundação Instituto Brasileiro de Geografia e Estatística. Departamento de Geografia. Folhas de Franca, Pedregulho, Capetinga, Jeriquara da coleção Carta do Brasil. Rio de Janeiro, 1971. esc. 1:50.000.

CASSOL, E.A. A experiência gaúcha no controle da erosão rural. In: SIMPÓSIO SOBRE O CONTROLE DA EROSÃO, 2., 1981, São Paulo. Anais... p.149-81.

COMISSÃO DE SOLOS. Levantamento de reconhecimento dos solos do Estado de São Paulo. Centro Nacional de Ensino e Pesquisa Agronômicas. Boletim Centro Nacional Pesquisa Agronômica, Rio de Janeiro, n.12, p.1-639, 1960.

FRANCA. Prefeitura. Clima e meio ambiente. Disponível em: <www.franca.sp.gov/cidade.html>. Acesso em: 28 maio 2002.

IBGE.Cidades@. Disponível em: <www.ibge.gov.br/cidadesat/default.php>. Acesso em: 28 maio 2002.

LOPES-VERGARA, M.L. Manual de fotogeologia. Madrid: Servicio de Publicaciones de la Junta de Energia Nuclear, 1971. 286 p.

NAKAZAWA, V.A.; FREITAS, C.G.L.; DINIZ, N.C. Carta geotécnica do Estado de São Paulo. São Paulo: Instituto de Pesquisas Tecnológicas, v.1 e 2, 1994. esc. 1:50.000. color. 22 p.

OLIVEIRA, J.B.; CAMARGO, M.N.; ROSSI, M.; CALDERANO FILHO, B. Classificação de solos usada em levantamentos pedológicos no Brasil. Brasília: Empresa Brasileira de Pesquisa Agropecuária, 1999.

POLITANO, W.; LOPES, L.R.; CORSINI, P.C.; SUETOMI, A.M. Avaliação, por fotointerpretação, da ocupação do solo do município de Jaboticabal - SP, no início da década 1980 e da sua variação no período 1962-1983. Científica, Jaboticabal, v.23, n.1, p.85-93, 1995.

POLITANO, W.; LATANZE, R.J.; LOPES, L.R.; AMARAL, C.; CORSINI, P.C.; SILVA, G.W. de L. Ocupação do solo e estados da erosão acelerada no município de Mococa, SP. Revista de Geografia, São Paulo, v.11, p.47-61, 1992.

SÃO PAULO. Conselho Estadual de Recursos Hídricos. Plano estadual de recursos hídricos: primeiro plano do Estado de São Paulo-1990-síntese. São Paulo: DAEE, 1990. 120 p.

SÃO PAULO. Governo do Estado de São Paulo. Secretaria da Indústria, Comércio, Ciência e Tecnologia. Mapa geomorfológico do Estado de São Paulo. São Paulo, 1981a. v.1, p.7-94. mapa color. esc. 1:500.000.

SÃo PAULO. Instituto de Pesquisas Tecnológicas do estado de São Paulo. Divisão de Minas e Geologia Aplicada. Mapa geológico do Estado de São Paulo. São Paulo, 1981b. v.1, p.1-124. Mapa color. esc. 1:500.000. 